\title{
Factors Effect on Metal Detecting System using Mobile Robot
}

\author{
Wael R. Abdulmajeed, PhD \\ Department of Mechatronics \\ Al-Khwarizmi Eng. College \\ University of Baghdad \\ Baghdad, Iraq
}

\author{
Mehdi A. Hussein \\ MSc.Student \\ Department of Mechatronics \\ Al-Khwarizmi Eng. College \\ University of Baghdad \\ Baghdad, Iraq
}

\begin{abstract}
The metal detection mobile robot has got to the summit of the utilized methods in landmines and unexploded ordnance detection techniques, while it is used in other applications like archeology, treasure and mines prospection and underground metallic services search in different scales. This paper uses a path planning, without supervisor robot at three environments. The path plan supposes that metal is safe so it cover the entire area in rectangle approach with detection of metal. The program which has been written in c++.net saves path of the robot and the detected metals locations in Microsoft Excel file. The program does not need a supervisor since it deals with all the possibilities of path planning. The three outdoor environments which were experimented are paved land, sand land and grassland.
\end{abstract}

The metal detection autonomous mobile robot has succeeded to move in desired navigation strategy. The experimental work shows that the increase of translation velocity leads to increase in error, the paved land has the least error and the sand land has the biggest error, the decrease in rotational velocity decreases the elapsed time in turnover and stroke and at low velocities the effects of the land types have diminished.

\section{Keywords}

Metal Detection, Mobile Robot, Autonomous, path planning.

\section{INTRODUCTION}

The autonomous mobile robot is a novel advance in metal detection ability researches. Considering the diversity aspects of utilization of the metal detection autonomous mobile robot, most of the approaches are dealt with development and utilization views; some are dealt with path planning and type of control: programmatically or by hardware techniques [1][3]; or dealt with the type of service, such as landmines and buried explosives, mines, precious metals or public services such as pipes and electrical cables [3]-[5]; some of which are dealt with the effect of the ground type such as mud or desert or jungle, or focused on certain regions [6]-[8]; and finally some are dealt with type of map representation and the resulting data and ways to take advantage of artificial intelligence [9]-[12]. Rajasekharan et al [13] proved that most of the researches that deal with metal detection robot had not met a certain guidelines and a majority of them had not made it to the outdoor fields for testing.

The purpose of this work is to investigate the accuracy of path planning, the effect of changing velocity and the environment effects, when Pioneer3-DX works with Smart Sensor AR924 using Advanced Robotics Interface for Application (ARIA).

\section{NAVIGATION STRATEGY}

This research depends on special ARIA based (c++.net) program to navigate the robot in a rectangular pattern. The rectangular searching process is based on the robot mapping a rectangular area, according to a predefined perimeter size of the map. The robot then scans the area with the metal detector by moving up and down the area in columns as wide as the robot. This enables complete area coverage to be accomplished. During the search process, the robot is constantly scanning for metallic objects in its path, if a metal is detected (robot.getAnalog ()$>0$ ), the robot saves the metal location and continues scanning.

\section{THE ALGORITHM SOFTWARE OF SLAM}

In this paper, (c++.net) was used to build algorithm Software for navigation and mapping: In navigation, some commands were built in $(\mathrm{c}++. n e t)$ to initialize the robot and control the motors to navigate the mobile robot in the plan while scanning the whole desired area with metal detection.

In mapping, mathematical equations were built as a command in (c++.net). These equations extracted text documents of data result and represent the mapping of the path of mobile robot and the position of the detected metal. The data of text documents are used in Microsoft excel to plot the result of path data in figure to show the result. Figure (1) shows the flowchart of the main program and Figure (2) shows the flowchart for subroutine program of navigation strategy: 




Figure (1) The flowchart of the main program

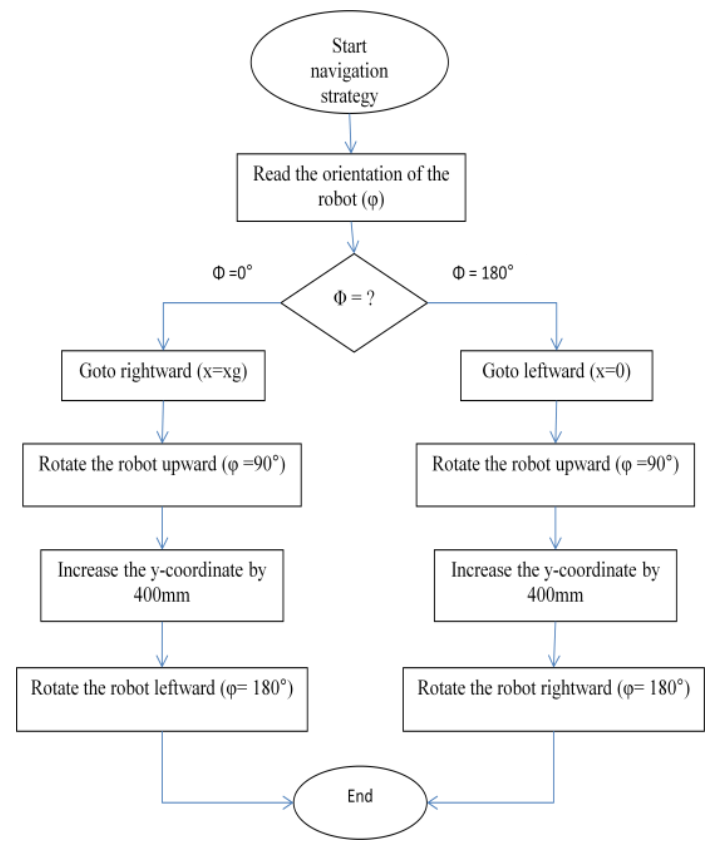

Figure (2) The flowchart of navigation strategy

\section{RESULTS AND DISCUSSION}

In this work, the metal detecting mobile robot navigates in paved land, sand land and grassland environments. The plan has the dimension of $(4 \times 2.4)$ meters, as shown in figure (3) and figure (4). It moves without a supervisor by using navigation strategy. Those cases used a program built in (c++.net) for navigation and for mapping.



Figure (3) a: paved land, b: sand land and c: grassland

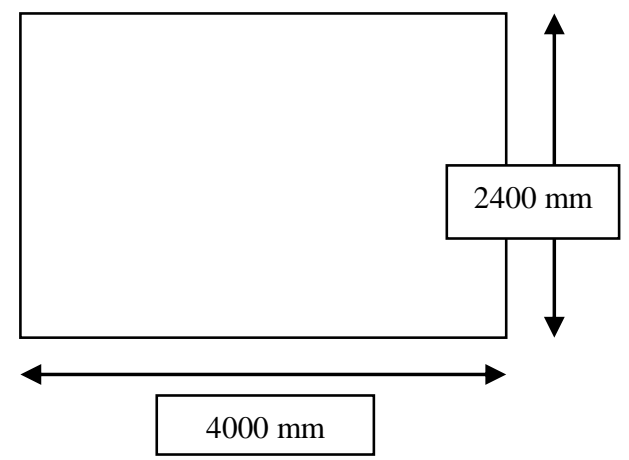

Figure (4) Map for navigation

Figure (5) shows the path planning and the detecting metals locations. Figure (6) shows the cumulative distance that the robot moved on the paved land with respect to time in different velocities. Figure (7) shows the cumulative distance that the robot moved with respect to time on the paved land, sand land and grassland with acceleration /deceleration $20 \mathrm{~mm} / \mathrm{s}^{2}$ and maximum velocity $300 \mathrm{~mm} / \mathrm{s}$. 


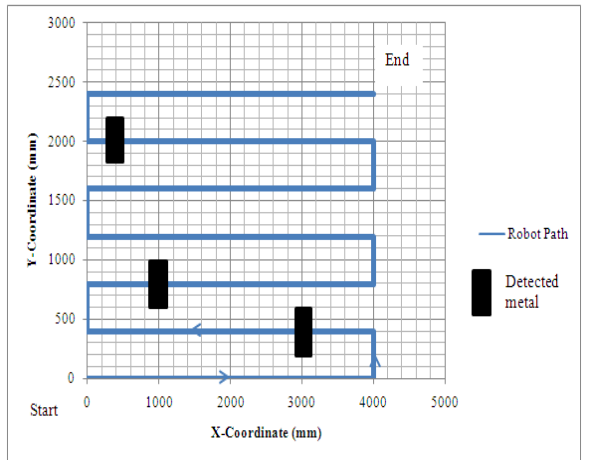

Figure (5) Path planning and detecting metals

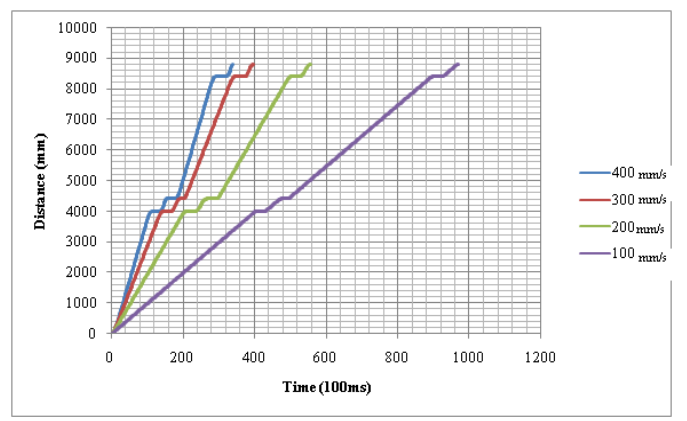

Figure (6) velocity change effect on motion for paved land

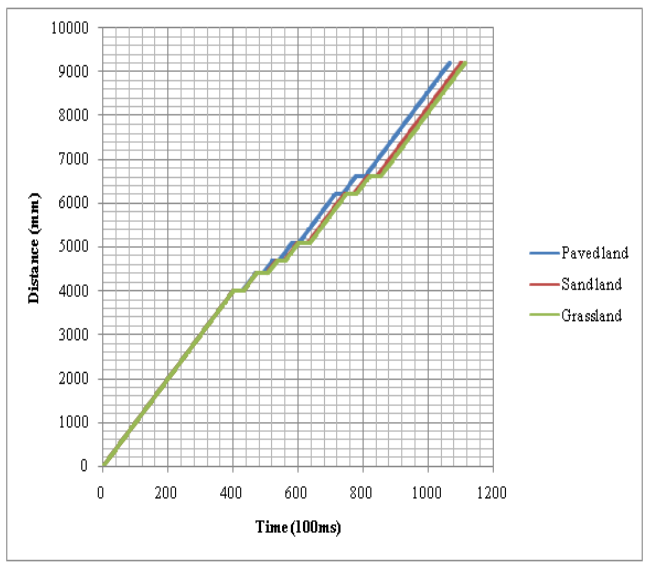

Figure (7) The land type effect on cumulative distance with time

Table (1) shows the time and points which are made by the robot for all the land types by different velocities. It also shows the error of the final position of the robot calculated with respect to the estimated location, i.e. $(\mathrm{Xg}$, $\mathrm{Yg})=(4000,2400)$ and $(\mathrm{Xr}, \mathrm{Yr})$ is the final robot position which is taken manually. Equation (1) shows how the error is calculated.

$e=\sqrt{(X g-X r)^{2}+(Y g-Y r)^{2}}$
Table (1) the time, points and error calculated for all experiments

\begin{tabular}{|c|c|c|c|c|}
\hline \multirow{2}{*}{ Land type } & $\begin{array}{c}\text { Translation } \\
\text { velocity } \\
(\mathrm{mm} / \mathrm{s})\end{array}$ & $\begin{array}{c}\text { Time } \\
\text { (seconds) }\end{array}$ & Points & Error (mm) \\
\hline \multirow{3}{*}{$\begin{array}{c}\text { Paved } \\
\text { land }\end{array}$} & 400 & 118.3 & 919 & 20 \\
\cline { 2 - 5 } & 300 & 134.4 & 1152 & 12 \\
\cline { 2 - 5 } & 200 & 196.7 & 1637 & 5 \\
\cline { 2 - 5 } Sand land & 100 & 335.1 & 3105 & 1 \\
\cline { 2 - 5 } & 300 & 149.3 & 1181 & 57 \\
\cline { 2 - 5 } Grassland & 200 & 196 & 1624 & 28 \\
\cline { 2 - 5 } & 200 & 342.3 & 3105 & 14 \\
\cline { 2 - 5 } & 100 & 344.1 & 3105 & 10 \\
\hline
\end{tabular}

Table (1) shows the inverse relation between the velocities and both the number of points and the time elapsed. The lower the velocity leads to the small amount of error. Also, it shows that the paved land has the smallest error while the grassland has the biggest one at the same velocity.

\section{CONCLUSIONS}

The navigation strategy made the robot cover the desired area with optimal path and no gaps were noticed as shown in figure (5). The error calculated has a direct proportionality value with velocity for all land types. The paved land has the lowest error calculated and the grassland has the biggest error calculated. The paved land has the lowest elapsed time and the grassland has the biggest elapsed time. The produced maps are accurate and mimic the reality.

\section{ACKNOWLEDGMENT}

This work has been supported by Mechatronics Department at Al-Khwarizmi Engineering College-University of Baghdad-Iraq.

\section{REFERENCES}

[1] Z. Najdovski, C. Mawson, H. Trinh, and S. Nahavandi, "Solution to Robotic Landmine Detection through Use of Path Planning and Motor Control," in World Automation Congress (WAC), Budapest, Hungary, 2006.

[2] K. L. Su, H. S. Su, S. W. Shiao, and J. H. Guo, "Motion planning for a landmine detection robot," Artif. Life Robot., vol. 16, no. 3, pp. 277-280, Dec. 2011.

[3] T. Fukuda, S. Sato, Y. Hasegawa, T. Matsuno, and Z. Zyada, "Motion Control of Landmine Detection Vehicle Equipped with Low-Ground-Pressure Tires," in MicroNanoMechatronics and Human Science, 2006 International Symposium on, 2006, pp. 1-6.

[4] S. Masunaga and K. Nonami, "Controlled Metal Detector Mounted on Mine Detection Robot," Int. J. Adv. Robot. Syst., vol. 4, no. 2, pp. 237-245, 2007.

[5] A. M. Kaneko, G. Endo, and E. F. Fukushima, "Landmine buried depth estimation by curve characterization of metal mine detector signals," in 2013 IEEE/RSJ International Conference on Intelligent Robots and Systems, 2013, pp. 5327-5332.

[6] R. Boon, "Metal matters," University of Leiden, Faculty of Archaeology, M.Sc thesis, 2013. 
[7] H. Preetz and V. Hennings, "Predicting metal detector performance for landmine clearance: soil magnetic map of Angola," Environ. Earth Sci., vol. 60, no. 7, pp. 14991508, Sep. 2009.

[8] M. A. Jaradat and M. N. Banisalim, "Autonomous Navigation Robot for Landmine Detection Applications," in Mechatronics and its Applications (ISMA), 2012 8th International Symposium, pp. 1-5.

[9] S. Larionova, L. Marques, and A. De Almeida, "Detection of Natural Landmarks for Mapping by a Demining Robot," in 2006 IEEE/RSJ International Conference on Intelligent Robots and Systems, 2006, pp. 4959-4964.

[10] V. Kumar and F. Sahin, "Cognitive Maps in Swarm Robots for The Mine Detection Application," SMC'03 Conf. Proceedings. 2003 IEEE Int. Conf. Syst. Man
Cybern. Conf. Theme - Syst. Secur. Assur. (Cat. No.03CH37483), vol. 4, pp. 3364-3369, 2003.

[11] H. Najjaran, N. Kircanski, and A. a. Goldenberg, "Map Building for a Terrain Scanning Robot," in Proceedings 2001 ICRA. IEEE International Conference on Robotics and Automation (Cat. No.01CH37164), 2001, vol. 4, pp. $3728-3733$.

[12] C. Zinggerling, J. M. M. Mirats-Tur, and A. CorominasMurtra, "GIS Map Based Mobile Robot Navigation in Urban Environments," Robot. 2009 ICAR, pp. 1-6, 2009.

[13] S. Rajasekharan and C. Kambhampati, "The Current Opinion on the use of Robots for Landmine Detection," in International Conference on Robotics \& Automation, Taipei, Taiwan, September 14-19, 2003, 2003, pp. 42524257. 